\title{
Surface Properties of Treponema pallidum in Relation to Phagocytosis by Human Polymorphonuclear Leucocytes in vitro
}

\author{
By A. COCKAYNE, ${ }^{*}$ C. W. PENN AND M. J. BAILEY \\ Department of Microbiology, University of Birmingham, South West Campus, \\ Birmingham B15 2TT, UK
}

(Received 13 May 1985; revised 8 August 1985)

\begin{abstract}
Surface charge and hydrophobicity of Treponema pallidum have been investigated in relation to phagocytosis by human polymorphonuclear leucocytes (PMNs) in vitro. The treponemal surface was relatively hydrophobic and negatively charged but despite these properties, phagocytosis, as assessed by luminol-enhanced chemiluminescence, was minimal in the absence of serum. Preopsonization of bacteria with serum reduced surface hydrophobicity but promoted phagocytosis, suggesting that specific immune mechanisms may be more important in controlling phagocytosis of $T$. pallidum in vitro than non-specific surface properties. $T$. pallidum evoked a much weaker chemiluminescence response from PMNs than the non-pathogenic treponeme Treponema phagedenis biotype Reiterii even though similar numbers of bacteria were phagocytosed, suggesting differences in the reactivity of the surface components of the two organisms toward PMNs. The reactivity of $T$. pallidum towards PMNs could be increased by removal of the bacterial outer membrane by Triton X-100 treatment. These observations reinforce the suggestion that the outer surface of $T$. pallidum is inherently inert.
\end{abstract}

\section{INTRODUCTION}

Syphilis differs from many other bacterial diseases in that early in infection the invading organism, Treponema pallidum, evokes little or no acute inflammatory response (Lukehart et al., 1980). Histological examination of tissue early in infection indicates that polymorphonuclear leucocyte (PMN) infiltration is limited and phagocytosis of treponemes is minimal, the vast majority of bacteria remaining extracellular despite a detectable humoral immune response (Penn, 1981; Hanff et al., 1983). It has been suggested that the lack of stimulation of PMN infiltration may be due to masking of treponemal antigens by acquisition of a coat of hostderived tissue components including proteins and mucopolysaccharides (Alderete \& Baseman, 1979; Fitzgerald et al., 1979), preventing recognition of antigens by antibody and complement and limiting phagocytosis. Opsonization of bacterial surfaces promotes phagocytosis and a role for anti- $T$. pallidum antibody in promotion of phagocytosis of this organism has been demonstrated in vitro (Musher et al., 1983; Lukehart \& Miller, 1978); blocking of antibody binding could therefore limit phagocytosis in vivo.

Bacterial-phagocyte interactions may also be influenced by non-specific physicochemical properties of the bacterial surface including surface charge and hydrophobicity (Beachey, 1980). These surface properties may be modified by the binding of serum components including complement and antibody (Stendahl et al., 1974; Stjernstrom et al., 1977). Although T. pallidum binds host serum components to its surface in vivo (Alderete \& Baseman, 1979), nothing is known of the influence of bound components on the physicochemical properties of the treponemal surface or their influence on phagocytosis of the organism. A combination of

\footnotetext{
Abbreviations: HBSS, Hanks` balanced salts solution; PEG, polyethylene glycol; P-PEG, polyethylene glycol palmitate; PMN, polymorphonuclear leucocyte.
} 
treponemal surface properties not conducive to phagocytosis could explain the limited interactions between PMNs and T. pallidum in vivo.

The influence of serum components on surface properties of $T$. pallidum and phagocytosis of the bacterium has therefore been investigated.

\section{METHODS}

Bacteria. The Nichols strain of T. pallidum was maintained by intratesticular passage in Californian rabbits and harvested as previously described (Penn \& Rhodes, 1982; Penn, 1983). Bacteria were used after storage in extraction medium $+0 \cdot 1 \%$ sodium azide for $48 \mathrm{~h}$ at $4{ }^{\circ} \mathrm{C}$. Treponema phagedenis biotype Reiterii ( $T$. phagedenis) was grown at $37^{\circ} \mathrm{C}$ in spirolate broth (Beckton Dickinson) supplemented with $5 \%(\mathrm{v} / \mathrm{v})$ newborn calf serum (Gibco). Before use bacteria were sedimented by centrifugation for $5 \mathrm{~min}$ at $11600 \mathrm{~g}$ in an MSE Microcentaur centrifuge and washed twice in the relevant buffer.

Investigation of surface properties of azide-killed T. pallidum. Surface properties were investigated by phase partitioning in PEG-Dextran two-phase systems and by electrostatic and hydrophobic interaction chromatography.

Phase partitioning. The methods used were those described by Albertsson et al. (1982). Phase systems were prepared in $64 \times 10 \mathrm{~mm}$ plastic tubes from stock solutions of $40 \%(\mathrm{w} / \mathrm{w})$ PEG 3350 (Sigma) and $20 \%(\mathrm{w} / \mathrm{w})$ Dextran T500 (Pharmacia). Surface charge and hydrophobicity were determined in systems containing varying amounts of $\mathrm{NaCl}$ (system A) and hydrophobically substituted PEG-palmitate (P-PEG - system B) (Shanbhag \& Johanssen, 1974) respectively. Isoelectric points were determined by the method of cross-partition described by Albertsson et al. (1982) (system C).

Phase systems were prepared by weighing polymer solutions into the tubes followed by the addition of relevant amounts of buffer, salts and bacterial suspension. The weight of each system was then made up to $1 \mathrm{~g}$ with sterile distilled water. The composition of the systems was (A) $6.75 \%(w / w)$ dextran, $6.5 \%(w / w)$ PEG, $10 \mathrm{~mm}$-sodium phosphate buffer, $\mathrm{pH} 7.0$, and 0 to $20 \mathrm{mM}-\mathrm{NaCl}$; (B) $7.5 \%$ (w/w) dextran, $6.5 \%$ (w/w) PEG, $3 \mathrm{mM}$-Tris $/ \mathrm{HCl}$ buffer, $\mathrm{pH} 7$, and 0 to $0.03 \%(\mathrm{w} / \mathrm{w})$ P-PEG; (C) as (A) but with $10 \mathrm{~mm}$-sodium citrate buffer, $\mathrm{pH} 3.0$ to 6.0 , and either $20 \mathrm{~mm}-\mathrm{NaCl}$ or $10 \mathrm{mM}-\mathrm{Na}_{2} \mathrm{SO}_{+}$. Approximately $1 \times 10^{8}$ bacteria, suspended in the relevant buffer, were added per system.

Systems were mixed by inversion 30 to 40 times and $100 \mu \mathrm{l}$ samples withdrawn for estimation of the total number of bacteria present. Tubes were then left to stand for $45 \mathrm{~min}$ at room temperature to allow partition to occur. The upper (PEG) phase was then sampled and, after diluting $1: 1$ with water, bacterial counts in all samples were determined microscopically in a Thoma counting chamber. The percentage of bacteria in the PEG phase was calculated from these counts and the volumes of the phases.

Electrostatic interaction chromatography. The method used was modified from Pedersen (1980). Packed volumes $(200 \mu \mathrm{l})$ of ion-exchange resin, pre-swollen and equilibrated in the appropriate buffer, and $0.3 \mathrm{ml}$ buffer containing $8 \times 10^{6}$ bacteria were mixed in $1.5 \mathrm{ml}$ volume capped polycarbonate tubes. Tubes were vortexed for $10 \mathrm{~s}$ and the resin beads allowed to settle at room temperature for $10 \mathrm{~min}$. The bacterial counts in the supernates above the beads, and in control tubes containing $0.3 \mathrm{ml}$ bacterial suspension and $0.2 \mathrm{ml}$ buffer, were determined microscopically and reduction of bacterial numbers in the presence of resin taken as a measure of adherence to the beads. Binding to QAE and DEAE Sephadex A50 and SP-Sephadex A25 was tested in $10 \mathrm{mM}$-sodium phosphate or $100 \mathrm{~mm}$-Tris/ $\mathrm{HCl}$ buffer, $\mathrm{pH} 6.8$. Binding to DEAE Sephadex A50 at different $\mathrm{pH}$ values was tested in $100 \mathrm{~mm}$ sodium citrate buffer $+100 \mathrm{~mm}-\mathrm{NaCl}$.

Hydrophobic interaction chromatography. Binding to Octyl-Sepharose CL 4B was tested as above in $100 \mathrm{~mm}$ Tris/ $\mathrm{HCl}$ buffer, $\mathrm{pH} 6.8$.

Interaction of T. pallidum and T. phagedenis with PMNs. PMNs were obtained from heparinized human venous blood by the dextran sedimentation method of Bridges et al. (1980). PMNs were washed twice in Hanks' balanced salts solution (without phenol red) +20 mM-HEPES, pH 7.2 (HBSS), and resuspended in HBSS at $1 \times 10^{6} \mathrm{ml}^{-1}$. T. pallidum or T. phagedenis $\left(1 \times 10^{8} \mathrm{ml}^{-1}\right)$ were pre-opsonized by incubation in $10 \%(\mathrm{v} / \mathrm{v})$ homologous serum in HBSS at $37^{\circ} \mathrm{C}$ for $15 \mathrm{~min}$ before mixing with PMNs. Some samples of serum were heated to $56^{\circ} \mathrm{C}$ for $30 \mathrm{~min}$ to inactivate the $\mathrm{C} 3$ component of the complement cascade, before mixing with bacteria. Similar opsonization was done with $10 \%(\mathrm{v} / \mathrm{v})$ control rabbit serum and a hyperimmune serum raised by repeated injection of $T$. pallidum into New Zealand White rabbits.

Phagocytosis was assayed by the method of luminol-enhanced chemiluminescence (Stevens et al., 1978). The concentration of luminol (5-amino-2,3-dihydro-1,4-phthalazinedione) in the reaction medium was $10^{-6} \mathrm{M}$. Volumes $(0.25 \mathrm{ml})$ of bacterial and PMN suspensions were mixed in $1.5 \mathrm{ml}$ capped polycarbonate tubes and incubated at $37^{\circ} \mathrm{C}$ on an end-over-end rotator at 30 r.p.m. Control tubes containing similar volumes of PMNs, but lacking bacteria, were also included in each set of assays. Chemiluminescence was measured after 5, 15 and $30 \mathrm{~min}$ incubation in a Beckman LS 700 scintillation counter using the 'in coincidence' mode with lower and upper 
window settings of 0 and 625 respectively. Results are expressed as counts per minute (c.p.m.). All assays were done in duplicate.

In preliminary experiments phagocytosis was also quantified by microscopy. Bacterial counts in reaction mixtures were determined in a Thoma counting chamber and a reduction in counts in the presence of PMNs compared with control tubes, containing bacteria only, was taken as a measure of phagocytosis.

Electron microscopy. Phagocytosis was confirmed by electron microscopy. After incubation with bacteria, PMNs were sedimented and extracellular bacteria removed by washing in HBSS. PMNs were fixed in $2 \%(\mathrm{v} / \mathrm{v})$ glutaraldehyde in 200 mosm-phosphate-buffered saline, $\mathrm{pH} 7 \cdot 2$, and post-fixed in $2 \%(\mathrm{v} / \mathrm{v})$ osmium tetroxide. The pellet was embedded in Araldite after dehydration through a series of graded alcohols and propylene oxide. Blocks were cured at $60^{\circ} \mathrm{C}$ overnight and sections cut on a Reichart Ultracut microtome. Sections were stained with uranyl acetate and lead citrate and examined in a Philips 201 electron microscope.

Triton treatment of $T$. pallidum. Bacteria were exposed to $0.2 \%(\mathrm{v} / \mathrm{v})$ Triton X-100 in $0.05 \mathrm{M}-\mathrm{Tris} / \mathrm{HCl}$ buffer, $\mathrm{pH} 8.0$, for $30 \mathrm{~min}$ at $37^{\circ} \mathrm{C}$ as described by Penn \& Rhodes (1982). Bacteria were then sedimented, washed three times and resuspended in HBSS to their original concentration.

Unless otherwise stated, data represent mean values $\pm \mathrm{SE}$ from at least three determinations and, where indicated, data were analysed statistically by the Mann-Whitney $\mathrm{U}$ test.

\section{RESULTS}

\section{Phagocytosis of treponemes by human PMNs}

Azide-killed $T$. pallidum, pre-opsonized with normal human serum, were readily phagocytosed by human PMNs as shown both by the reduction of treponemal numbers remaining free in suspension with time and the marked PMN chemiluminescent response (Fig. 1). Microscopic examination of samples of reaction mixtures showed that $<5 \%$ of PMNs had T. pallidum visibly adherent to their outer surface after incubation, suggesting that the majority of bacteria removed from the supernates had been ingested. Also phagocytosis was confirmed by electron microscopy which showed numerous treponemes inside phagocytic vacuoles (Fig. 2). The chemiluminescent response obtained in replicate experiments varied considerably, e.g. after $15 \mathrm{~min}$ incubation in normal human serum, mean response $=207338$ c.p.m., $\mathrm{SE}=$ 48900 c.p.m., $n=19$. The pattern of results obtained in replicate experiments was, however, similar and differences obtained with different serum treatments were reproducible. Chemiluminescence in the presence of normal human serum was measured in each set of assays and was used as a standard against which responses produced by other serum treatments were compared.

The response obtained was influenced by the presence of heat-labile serum components and was markedly reduced in heat-treated serum $(P<0.05$ at 5 and $15 \mathrm{~min})$ (Fig. $3 b)$. The strongest response was observed when bacteria were pre-opsonized with hyperimmune anti- $T$. pallidum rabbit serum $(P<0.01$ at $5 \mathrm{~min})$ (Fig. $3 a$ ). Chemiluminescence in the absence of serum was minimal $(P<0.05$ at all time points) (Fig. $3 c)$. Triton-treated $T$. pallidum evoked a much stronger chemiluminescence in the presence of normal human serum than intact bacteria $(P<$ 0.05 at $5 \mathrm{~min}$ ) (Fig. 4).

T. phagedenis was also readily phagocytosed in the presence of normal human serum (Fig. 1). Although similar numbers of both bacteria were phagocytosed the chemiluminescence evoked by $T$. phagedenis was much stronger than that for $T$. pallidum (Fig. 1).

\section{Surface properties of $T$. pallidum}

Phase partitioning. The results of partitioning studies of $T$. pallidum in PEG-Dextran twophase systems are shown in Fig. 5. Partitioning of bacteria was influenced by increasing concentrations of both $\mathrm{NaCl}$ and P-PEG, indicating a negatively charged, relatively hydrophobic cell surface (Fig. $5 a, b$ ). In preliminary experiments partitioning of bacteria of known surface properties (two Salmonella typhimurium isolates designated 395 MS and MR 10, kindly donated by E. Kihlstrom, Linkoping, Sweden) was tested in these systems. T. pallidum partitioned in a similar manner to the relatively hydrophobic, negatively charged strain MR 10 (Magnusson et al., 1977) (data not shown).

The negative surface charge was confirmed by the method of cross-partitioning in phase systems containing either $\mathrm{NaCl}$ or $\mathrm{Na}_{2} \mathrm{SO}_{4}$ (Albertsson et al., 1982). The isoelectric point of the 


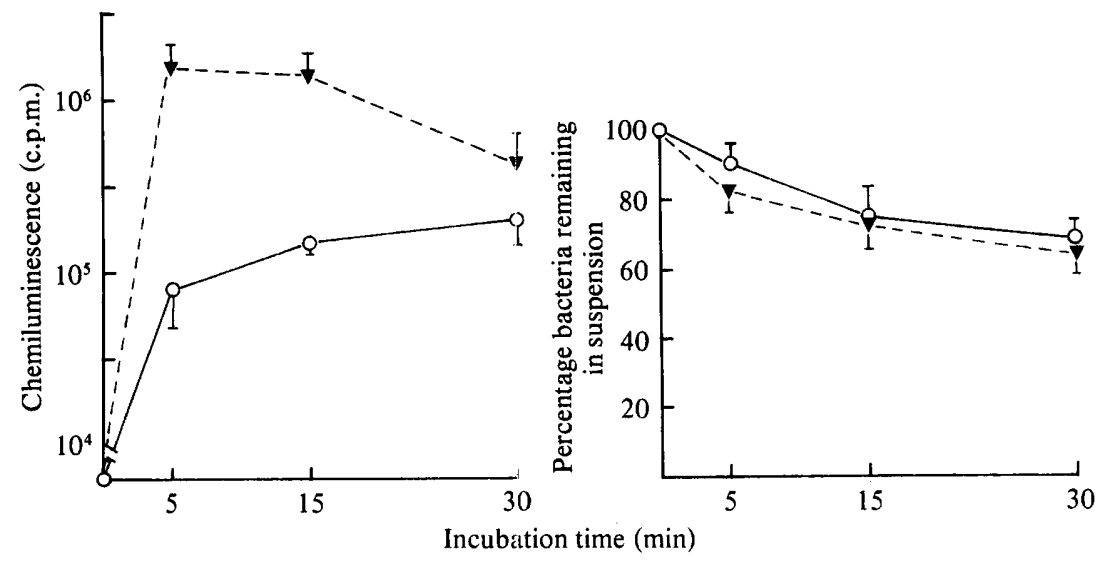

Fig. 1. Correlation of phagocytic uptake and chemiluminescence response of PMNs toward $T$. pallidum $(O)$ and $T$. phagedenis $(\nabla)$. Bars denote sems.

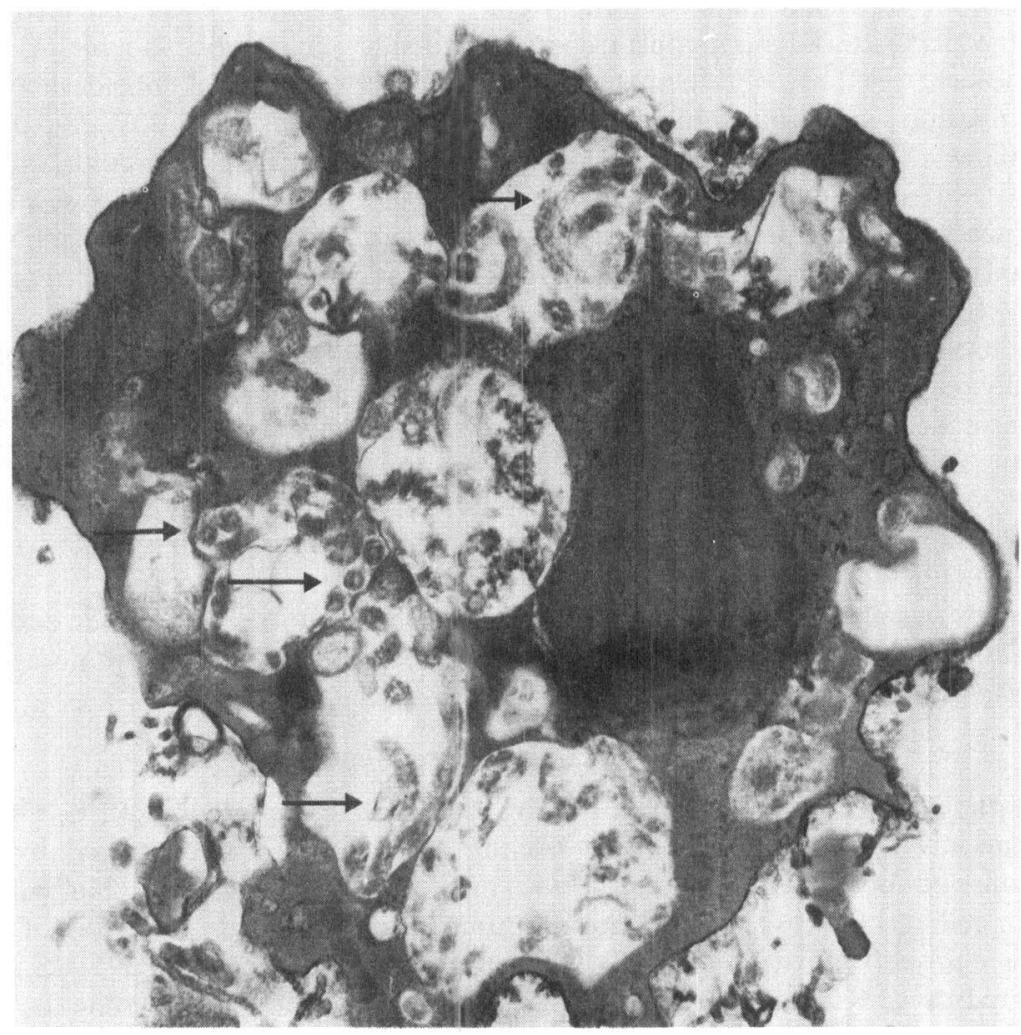

Fig. 2. Electron micrograph of a section through a PMN showing numerous phagocytic vacuoles containing ingested treponemes (arrowed). Magnification $\times 15000$. 

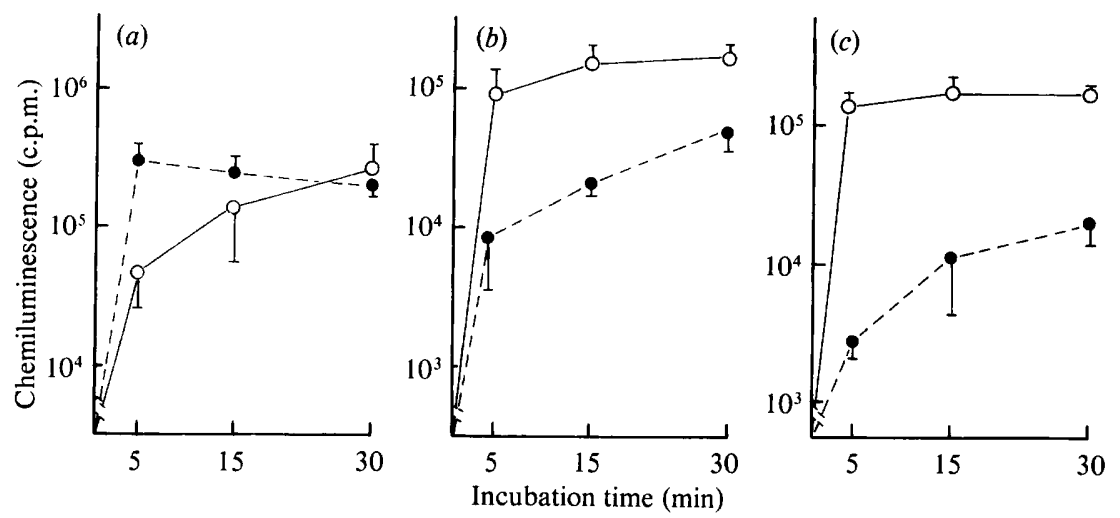

Fig. 3. Effect of serum factors on chemiluminescence response of PMNs to $T$. pallidum. Response in normal human serum $(O)$ is compared with that in $(a)$ hyperimmune rabbit serum, $(b)$ heat-treated human serum and $(c)$ no serum $(\mathbf{O})$. Bars denote SEMs.

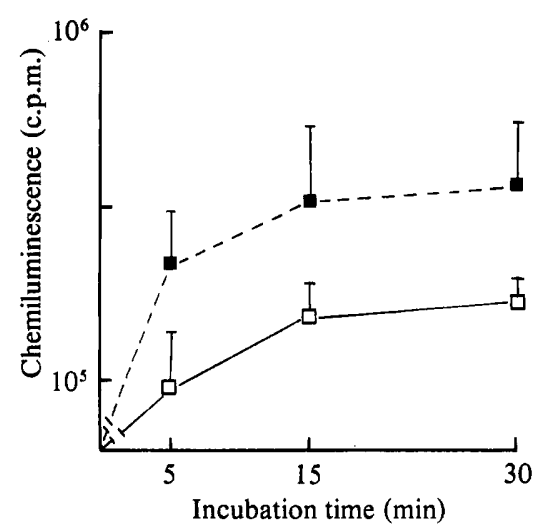

Fig. 4. Effect of Triton X-100 treatment of T. pallidum on PMN chemiluminescence in the presence of normal human serum. $\square$, Control; $\square$, Triton X-100 treated $T$. pallidum. Bars denote SEMs.

treponemal surface obtained by this method was $3.56 \pm 0.3$ (Fig. $5 c$ ). Some variation was observed in the isoelectric point determined in replicate experiments due to the tendency of bacteria to clump at low $\mathrm{pH}$ values.

Electrostatic interaction chromatography. T. pallidum bound to both positively charged ionexchange resins DEAE Sephadex A50 and QAE Sephadex A50 (Fig. 6a). Bound treponemes were readily visible by phase-contrast microscopy, adhering to resin beads. Binding was markedly influenced by the $\mathrm{NaCl}$ concentration of the buffer. Minimal binding to Sephadex CL 4B or SP-Sephadex A25 was also detected (data not shown). Binding to DEAE Sephadex $\mathrm{A} 50$ was influenced by buffer $\mathrm{pH}$ and was lowest at values around $\mathrm{pH} 3$, a value similar to that obtained by cross-partitioning for the tentative isoelectric point of the treponemal surface (Fig. $6 b$ ). Standard deviations in these experiments ranged from 0 to $13 \%$.

Hydrophobic interaction chromatography. T. pallidum bound to the hydrophobic gel OctylSepharose CL 4B, although bacteria bound in relatively small numbers and only in the presence of high $\mathrm{NaCl}$ concentrations (Fig. 6c).

Effect of serum binding on surface properties and phagocytosis of T. pallidum

As pre-opsonization of $T$. pallidum with sera from various sources influenced PMN chemiluminescence, the effect of similar treatments on the surface properties of $T$. pallidum was investigated to try to correlate changes in surface properties with variations in the phagocytic 

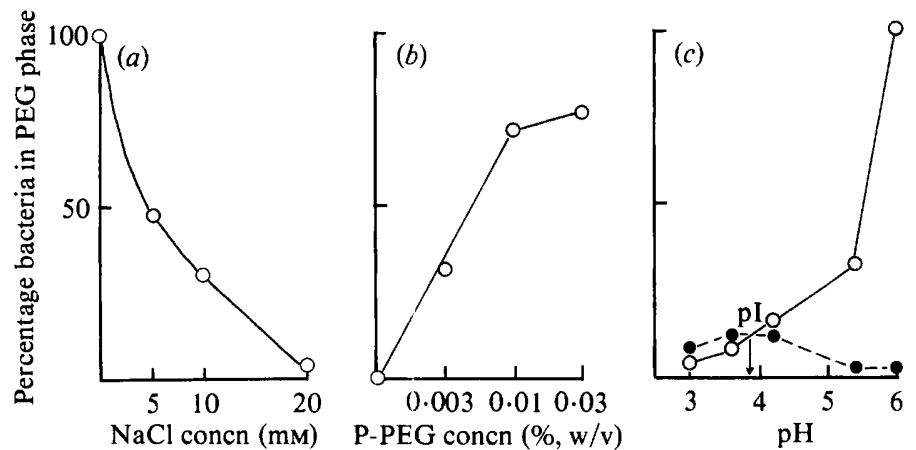

Fig. 5. Partitioning of $T$. pallidum in PEG-Dextran two-phase systems. (a) With $\mathrm{NaCl}$, (b) with $\mathrm{P}$ -

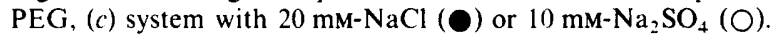

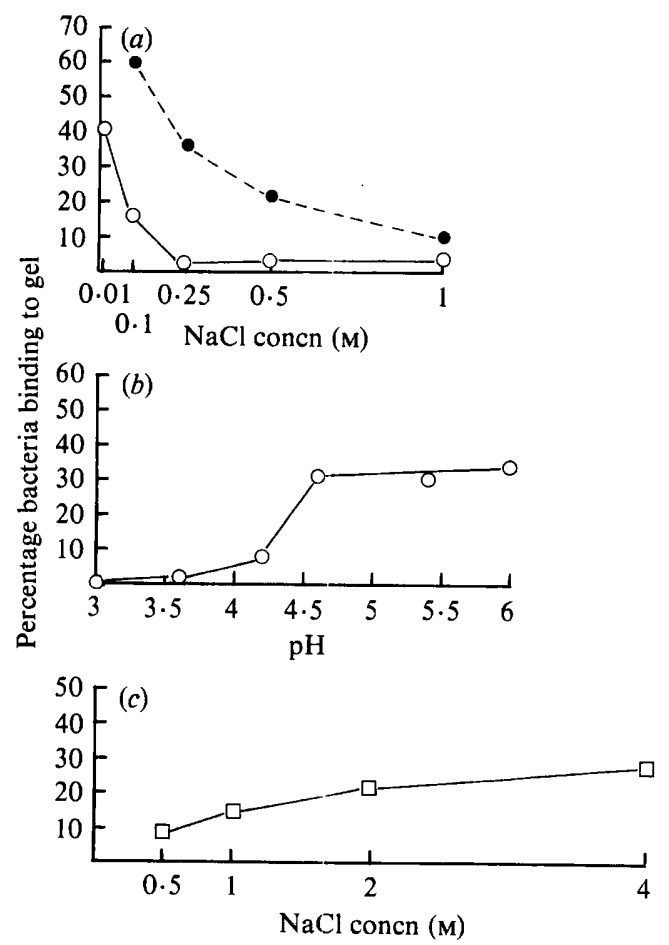

Fig. 6. (a) Effect of $\mathrm{NaCl}$ concentration on binding of $T$. pallidum to QAE (O) and DEAE (O) Sephadex. (b) Effect of $\mathrm{pH}$ on binding of $T$. pallidum to DEAE Sephadex. (c) Effect of $\mathrm{NaCl}$ concentration on binding of $T$. pallidum to Octyl-Sepharose CL $4 \mathrm{~B}$.

response. Bacteria were pre-opsonized with $10 \%$ serum in $\mathrm{HBSS}$ for $15 \mathrm{~min}$ at $37^{\circ} \mathrm{C}$, sedimented and washed three times in HBSS before resuspension in the relevant buffer and addition to the phase systems. In contrast to $T$. pallidum in the absence of serum, bacteria pre-opsonized with normal human serum or hyperimmune rabbit serum, both previously found to promote phagocytosis, showed a marked reduction in surface hydrophobicity as determined in P-PEGDextran two-phase systems. In the absence of serum, $98 \pm 15 \%$ (SD) of bacteria partitioned into the P-PEG phase compared with $24 \pm 15 \%$ pre-opsonized with normal human serum and $20 \%$ (single observation) pre-opsonized with hyperimmune rabbit serum. In contrast, pretreatment of bacteria with heat-treated human serum had no effect on surface hydrophobicity, $87 \pm 19 \%$ of bacteria partitioning in the P-PEG phase. No effect of these treatments on surface charge was observed (results not shown). 


\section{DISCUSSION}

Our observations on the interactions of $T$. pallidum with human PMNs assessed by a chemiluminescence method are in close agreement with those previously reported by Musher $e t$ al. (1983). Both serum antibody and heat-labile complement components promoted phagocytosis in vitro. Promotion of phagocytosis by normal human serum correlates well with previous reports of the presence of neutralizing antibody in normal serum (Hederstedt, 1976) possibly directed against antigens common to both commensal treponemes and T. pallidum (Strandberg Pedersen et al., 1981). Paradoxically however, it has proved impossible to detect binding of specific anti- $T$. pallidum antibody to intact treponemes by immunofluorescence (Penn \& Rhodes, 1982), even though the observed effects on phagocytosis and surface properties suggest binding has occurred. Further studies with immunogold labelling techniques have also failed to detect antibody binding to azide-killed $T$. pallidum (unpublished observations). It is conceivable that binding of very small quantities of antibody, below levels detectable by these methods, may be sufficient to promote phagocytosis of $T$. pallidum.

We have also observed differences in the chemiluminescence response of PMNs toward $T$. pallidum and a non-pathogenic cultivable treponeme $T$. phagedenis. Although the pattern of responses seen with both bacteria in our studies was similar (Fig. 1) the strength of the chemiluminescent response obtained with $T$. phagedenis was much greater than was observed with $T$. pallidum. The increased response did not appear to be due to greater phagocytosis of $T$. phagedenis since the kinetics of uptake for both bacteria were similar. One possibility is that phagocytosis of $T$. phagedenis stimulates a stronger oxidative metabolic burst than uptake of $T$. pallidum, resulting in increased chemiluminescence. $T$. pallidum and $T$. phagedenis differ in size and the increase in chemiluminescence could be partly attributed to the greater biomass of phagocytosed $T$. phagedenis. However, a second possibility exists that the outer surface of $T$. phagedenis is in some way more reactive towards PMNs than that of $T$. pallidum. The relatively inert nature of the $T$. pallidum surface is supported by previously published reports of the resistance of viable intact treponemes to reaction with antibody (Penn, 1981) and resistance of viable $T$. pallidum to surface iodination (Penn et al., 1985). The inert nature of the $T$. pallidum surface is supported by the observation in this study that Triton-treated $T$. pallidum promoted a much stronger chemiluminescence than intact bacteria (Fig. 4). Triton treatment removes the outer membrane of $T$. pallidum exposing antigens normally inert or cryptic in the intact organism (Penn \& Rhodes, 1982). Furthermore, comparison of the surface composition of $T$. pallidum and $T$. phagedenis (Bailey et al., 1985) has shown the presence of a smooth type lipopolysaccharide in $T$. phagedenis but not in $T$. pallidum. The apparent lack of lipopolysaccharide at the $T$. pallidum surface may contribute to the relatively weak chemiluminescence response elicited by $T$. pallidum compared with $T$. phagedenis, the initial lack of reactivity towards PMNs observed in vivo and also to treponemal surface hydrophobicity.

The combination of phase partitioning in PEG-Dextran two-phase systems and ionic and hydrophobic interaction chromatography suggests that the native treponemal surface in the absence of serum is negatively charged and relatively hydrophobic. Although all the methods used to assess surface charge gave similar results, some discrepancy was observed between results obtained for surface hydrophobicity by the two methods used. This discrepancy may be explained by the observation that phase partitioning measures overall surface hydrophobicity rather than localized regions of hydrophobic residues involved in binding to Octyl-Sepharose (Miorner et al., 1982).

Negative charge and a relatively hydrophobic surface favour phagocytosis for a number of bacteria (Stendahl et al., 1973; Van Oss, 1978). In contrast, phagocytosis of $T$. pallidum in the absence of serum was minimal, suggesting that non-specific surface properties may be of secondary importance to specific immunological reactions in promoting phagocytosis. The observation that opsonization with normal human serum reduced surface hydrophobicity of $T$. pallidum whilst promoting phagocytosis supports this view, although the mechanism by which hydrophobicity is reduced remains unknown. A similar apparent lack of correlation between hydrophobicity and liability to phagocytosis has been reported for some group A streptococci 
where a major surface component, the hydrophobic $\mathrm{M}$ protein, appears to confer resistance to phagocytosis (Speert et al., 1981) possibly by masking antigens and preventing binding of antibody and complement. The outer membrane of $T$. pallidum could have a similar role in vivo, as evidenced by the lack of reactivity of freshly isolated treponemes with antibody (Penn \& Rhodes, 1982) and the increased reactivity towards PMNs of Triton-treated bacteria. The promotion of phagocytosis by antibody and complement observed in vitro may be the result of exposure of antigens due to modification or damage of the treponemal surface during the extraction and washing procedures necessary for the preparation of bacteria for these assays. Such modification could probably occur without loss of treponemal motility and could explain our preliminary observations that viable treponemes were phagocytosed as readily as azidekilled bacteria and also behaved similarly in phase-partitioning assays (data not shown). Furthermore, washing may remove loosely-bound host tissue components which in vivo could contribute to the lack of surface reactivity by influencing surface properties and the binding of serum factors. In particular, a coat of host proteins or mucopolysaccharides could prevent the interaction between bound complement components and the Fc receptors on the phagocyte surface by simple steric hindrance, as suggested for capsules of some other pathogens (Edebo et al., 1981). Modification of the hydrophobic treponemal surface by binding of hydrophilic mucopolysaccharides (Ofek et al., 1983) could also further reduce the tendency for interaction with PMNs in the absence of serum.

Thanks are due to Mrs J. Gem and Mr D. Ruffles for excellent technical support and to the Medical Research Council for provision of a training fellowship (A.C.).

\section{REFERENCES}

Albertsson, P. A., Andersson, B., Larson, C. \& Akerlund, H. E. (1982). Phase partition - a method for purification and analysis of cell organelles and membrane vesicles. Methods of Biochemical Analysis 28, $115-150$.

Alderete, J. F. \& Baseman, J. B. (1979). Surfaceassociated host proteins on virulent Treponema pallidum. Infection and Immunity 26, 1048-1056.

Bailey, M. J., Penn, C. W. \& Cockayne, A. (1985). Evidence for the presence of lipopolysaccharide in Treponema phagedenis (biotype Reiterii) but not in $T$. pallidum Nichols. FEMS Microbiology Letters 27, $117-121$.

BEACHEY, E. H. (editor) (1980). Bacterial adherence. In Receptors and Recognition Series B, vol. 6. London: Chapman \& Hall.

Bridges, C. G., Dasilva, G. L., Yamamura, M. \& Valdimarsson, H. (1980). A radiometric assay for the combined measurement of phagocytosis and intracellular killing of Candida albicans. Clinical and Experimental Immunology 42, 226-233.

Edebo, L., Normann, B., Skogh, T. \& Stjernstrom, I. (1981). Properties of antibodies of different immunoglobulin classes in relation to opsonization. Monographs in Allergy 17, 48-70.

FitzGerald, T. J., Johnson, R. C. \& Ritzi, D. M. (1979). Relationship of Treponema pallidum to acidic mucopolysaccharides. Infection and Immunity 24, 252-260.

Hanff, P. A., Miller, J. N. \& Lovett, M. A. (1983). Molecular characterization of common treponemal antigens. Infection and Immunity 40, 825-828.

HederstedT, B. (1976). Studies on the Treponema pallidum immobilizing activity in normal human serum. 3. The kinetics of the immobilization reaction of normal and immune sera. Acta patholo- gica et microbiologica scandinavica, Section C 84, 142147.

Lukehart, S. A. \& Miller, J. N. (1978). Demonstration of the in vitro phagocytosis of Treponema pallidum by rabbit peritoneal macrophages. Journal of Immunology 121, 2014-2024.

Lukehart, S. A., Baker-Zander, S. A., CheriLLOYD, R. M. \& SELl, S. (1980). Characterization of lymphocyte responsiveness in early experimental syphilis. II. Nature of cellular infiltration and Treponema pallidum distribution in testicular lesions. Journal of Immunology 124, 461-467.

Magnusson, K. E., Stendahl, O., Tagesson, C., EDEBo, L. \& JohANSSON, G. (1977). The tendency of smooth and rough Salmonella typhimurium bacteria and lipopolysaccharide to hydrophobic and ionic interaction as studied in aqueous polymer two-phase systems. Acta pathologica et microbiologica scandinavica, Section B 85, 212-218.

Miorner, H., Albertsson, P. \& Kronvall, G. (1982). Isoelectric points and surface hydrophobicity of Gram-positive cocci as determined by crosspartition and hydrophobic affinity partition in aqueous two-phase systems. Infection and Immunity 36, 227-234.

Musher, D. M., Hague-Park, M., Gyorkey, F., ANDERSon, D. C. \& BAughn, R. E. (1983). The interaction between Treponema pallidum and human polymorphonuclear leukocytes. Journal of Infectious Diseases 147, 77-86.

OfEK, I., WhitNaCK, E. \& Beachey, E. H. (1983). Hydrophobic interactions of group A streptococci with hexadecane droplets. Journal of Bacteriology 154, 139-145.

Pedersen, K. (1980). Electrostatic interaction chromatography; a method for assaying the relative surface 
charges of bacteria. FEMS Microbiology Letters 12, 365-367.

PenN, C. W. (1981). Avoidance of host defences by Treponema pallidum in situ and on extraction from infected rabbit testes. Journal of General Microbiology 126, 69-75.

PenN, C. W. (1983). The use of the rabbit as a model for syphilis infection. In Experimental Bacterial and Parasitic Infections, pp. 145-151. Edited by G. Keusch \& T. Wadstrom. Amsterdam: Elsevier Biomedical.

Penn, C. W. \& Rhodes, J. G. (1982). Surfaceassociated antigens of Treponema pallidum concealed by an inert outer layer. Immunology 46, 9-16.

Penn, C. W., Cockayne, A. \& Bailey, M. J. (1985). The outer membrane of Treponema pallidum: biological significance and biochemical properties. Journal of General Microbiology 131, 2349-2357.

Shanbhag, V. F. \& Johanssen, G. (1974). Specific extraction of human serum albumin by partition in aqueous biphasic systems containing polyethylene glycol bound ligand. Biochemical and Biophysical Research Communications 61, 1141-1146.

Speert, D. P., Quie, P. G. \& Wannamaker, L. W. (1981). Enhanced phagocytosis of group A streptococci $M$ type 6 by oleic acid. Journal of Infectious Diseases 143, 570-571.

Stendahl, O., Tagesson, C. \& Edebo, M. (1973). Partition of Salmonella typhimurium in a two- polymer aqueous phase system in relation to liability to phagocytosis. Infection and Immunity 8, 36-41.

Stendahl, O., Tagesson, C. \& Edebo, M. (1974). Influence of hyperimmune immunoglobulin $G$ on the physicochemical properties of the surface of Salmonella typhimurium 395 MS in relation to interaction with phagocytic cells. Infection and Immunity 10, 316-319.

Stevens, P., Winston, I. J. \& Van Dyke, K. (1978). In vitro evaluation of opsonic and cellular granulocyte function by luminol-dependent chemiluminescence: utility in patients with severe neutropenia and cellular deficiency states. Infection and Immunity 22, 4l-51.

Stjernstrom, I., Magnusson, K. E., Stendahl, O. \& TAGESSON, C. (1977). Liability to hydrophobic and charge interaction of smooth Salmonella typhimurium 395 MS sensitized with anti-MS immunoglobulin G and complement. Infection and Immunity 18, 261265.

Strandberg Pedersen, N. N., Axelsen, N. H. \& SAnd Pedersen, C. (1981). Antigenic analysis of Treponema pallidum: cross reactions between individual antigens of $T$. pallidum and $T$. reiter. Scandinavian Journal of Immunology 13, 143-150.

Van Oss, C. J. (1978). Phagocytosis as a surface phenomenon. Annual Review of Microbiology 32, 1939. 